NBER WORKING PAPER SERIES

\author{
OPTIMAL CHOICE OF MONETARY \\ POLICY INSTRUMENTS IN A \\ MACROECONOMETRIC MODEL
}

\author{
Ray C. Fair
}

Working Paper No. 2150
NATIONAL BUREAU OF ECONOMIC RESEARCH 1050 Massachusetts Avenue Cambridge, MA 02138
February 1987

The research reported here is part of the NBER's research program in Economic Fluctuations. Any opinions expressed are those of the author and not those of the National Bureau of Economic Research. 
NBER Working Paper \#2150

\section{Optimal Choices of Monetary Policy Instruments in a Macroeconometric Model}

\section{$\underline{\text { ABSTRACT }}$}

This paper uses stochastic simulation and my U.S. econometric model to examine the optimal choice of monetary policy instruments. Are the variances, covariances, and parameters in the model such as to favor one instrument over the other, in particular the interest rate over the money supply? The results show that the interest rate and the money supply are about equally good as policy instruments in terms of minimizing the variance of real GNP. The variances of some of the components of GNP are, however, much larger when the money supply is the policy instrument, as is the variance of the change in stock prices. Therefore, if one's loss function is expanded beyond simply the variance of real GNP to variances of other variables, the interest rate policy does better. The results thus provide some support for what seems to be the Fed's current choice of using the interest rate as its primary instrument.

Stochastic simulation is also used to estimate how much of the variance of real GNP is due to the error terms in the demand for money equations. The results show that the contribution is not very great even when the money supply is the policy instrument.

\author{
Ray C. Fair \\ Cowles Foundation \\ Box 2125, Yale Station \\ New Haven, CT 06520
}


January 1987

OPTIMAL CHOICE OF MONETARY POLICY INSTRUMENTS IN A MACROECONOMETRIC MODEL ${ }^{1}$

by

Ray C. Fair

\section{Introduction}

It has been nearly twenty years since Poole (1970) wrote his classic article on the optimal choice of monetary policy instruments in a stochastic IS-LM model. Poole assumed that the monetary authority (henceforth called the Fed) can control the interest rate or the money supply exactly. These are the two "instruments" of monetary policy. If the aim is to minimize the squared deviation of real output from its target value, Poole showed that the choice of the optimal instrument depends on the variance of the error term in the IS function, the variance of the error term in the LM function, the covariance of the two error terms, and the size of the parameters in the two functions.

Most people would probably agree that between about October 1979 and October 1982 the Fed tried to use the money supply as its primary instrument. This attempt does not appear to have been successful in the sense that since about October 1982 the Fed seems to have gone back to using the interest rate as its primary instrument. If the interest rate has won out, it is interesting to ask if this decision can be justified on the basis of the Poole analysis. Is the economy one in which the relevant variances, covariances, and parameters are such as to lead, a la the Poole analysis, to the optimal instrument being the interest rate?

${ }^{1}$ The research described in this paper was financed by a grant from the National Science Foundation. I am indebted to Lewis Alexander for helpful discussions regarding the subject matter of this paper. 
The purpose of this paper is to examine this question using my U.S. econometric model. Are the variances, covariances, and parameters in the model such as to favor one instrument over the other, in particular the interest rate over the money supply? This question can be examined in an econometric model by the use of stochastic simulation. Interestingly enough, Poole's analysis has never been tried on an actual econometric model. The closest study in this respect is that of Tinsley and von zur Muehlen (1983), although they did not analyze the same question that Poole did. $^{2}$ Other studies that have extended Poole's work, such as those of Turnovsky (1975) and Yoshikawa (1981), have been primarily theoretical.

The results show that the interest rate and the money supply are about equally good as policy instruments in terms of minimizing the variance of real GNP. It does not matter very much which of the two variables is used. Concentrating on the variance of GNP does, however, mask some important differences between the two policies. The variances of some of the components of GNP are much larger when the money supply is the policy instrument. Likewise, the variance of the change in stock prices is much larger when the money supply is the instrument. If one's loss function is

2 In their stochastic simulation experiments, Tinsley and von zur Muehlen always used the interest rate (the Federal Funds rate) as the policy instrument. They used this instrument to target a particular variable, called an "intermediate" target. The intermediate targets they tried are the monetary base, three definitions of the money supply, nominal GNP, and the Federal Funds rate itself. For each of these target choices, they examined how well the choice did in minimizing the squared deviations of the unemployment rate and the inflation rate from their target values. The unemployment rate and the inflation rate are the "ultimate" targets. In the present study the aim is to see how well the interest rate does when it is used as the policy instrument in minimizing the squared deviations of real output from its target value compared to how well the money supply does when it is used as the policy instrument. This is the question that Poole examined. 
expanded beyond simply the variance of GNP to the variances of other variables, the interest rate does seem to win out. These results are discussed in Section III.

Stochastic simulation can also be used to answer the following question. For the case in which the money supply is the policy instrument, how much of the variance of GNP is due to the error terms in the demand for money equations? This question is equivalent in Poole's analysis to the question of how much of the loss is due to shocks to the LM function. Results that pertain to this question are presented in Section IV.

\section{The Model}

My model is described in detail in Fair (1984), and it will only be briefly discussed here. The model has been estimated through 1986 II for this study. The beginning quarter is $1954 \mathrm{I}$, and so there are 130 sample observations. There are 30 structural equations, estimated by two stage least squares, and 98 identities.

The model accounts for all flows of funds among the sectors and all balance-sheet constraints. This is done by linking the National Income Accounts to the Flow of Funds Accounts. This allows one to deal directly with the three "tools" of the Fed: the discount rate, the reserve requirement rate, and the amount of government securities in the hands of the public. This third tool, denoted AG in the model, is the "open-marketoperations" variable. It is the main variable used by the Fed in practice to manipulate the money supply and interest rates. The discount rate and the reserve requirement rate are fairly minor tools, and they are always taken to be exogenous in the model. 
In the basic version of the model there is an estimated interest rate reaction function. The reaction function is an equation with the short term interest rate (the three-month Treasury bill rate) on the left hand side and variables that are postulated to affect Fed behavior on the right hand side. According to this equation, the Fed "leans against the wind" in the sense that it raises the bill rate as real growth increases, labor markets become tighter, inflation increases, and the lagged growth rate of the money supply increases. In this version of the model both the money supply and the interest rate are endogenous. The money supply is determined by the demand for money equations and the interest rate is determined by the reaction function. Monetary policy is thus endogenous in this version. The openmarket-operations variable $A G$ is also endogenous. Its value each quarter is whatever is needed to have the interest rate be the value predicted from the interest rate reaction function.

It is possible to drop the interest rate reaction function from the model and make some other assumption about monetary policy. For purposes of this paper, two assumptions are considered. One is that the interest rate is exogenous, and the other is that the money supply is exogenous. In both of these cases $A G$ is still endogenous. Its value each quarter is whatever is needed to have either the interest rate target be met or the money supply target be met.

It will be useful to consider briefly how interest rates enter the model. There are four interest rates in the model: the discount rate, which is always exogenous; the bill rate; and two long term rates, the AAA corporate bond rate and a mortgage rate. The long term rates are determined by standard term-structure-of-interest-rate equations. Each long rate is a 
function of current and past values of the short rate.

There are two demand for money equations in the model, one for the household sector and one for the firm sector. The equations are fairly standard. The demand for real money balances is a function of the short term interest rate, a transactions variable, and the lagged dependent variable. For the household sector the transactions variable is real disposable income, and for the firm sector the transactions variable is the real value of sales. "Money" includes both demand deposits and currency. There is also a separate demand for currency equation, where the demand for currency is a function of the short term interest rate, a transactions variable, and the lagged dependent variable. There is a bank borrowing equation in the model, where bank borrowing from the Fed is a positive function of the difference between the bill rate and the discount rate. These four equations will be referred to as the "money equations." of the four, the two demand for money equations are by far the most important; the other two play a fairly minor role in the model. The money data used in the model are from the Flow of Funds Accounts and are end-of-quarter data.

The bill rate (as a measure of short term interest rates) appears as an explanatory variable in the nondurables consumption equation, and the mortgage rate (as a measure of long term interest rates) appears as an explanatory variable in the durables consumption equation and the housing investment equation. In addition, the mortgage rate appears as an explanatory variable in the demand for imports equation. (The interest rate coefficients are all negative.) The change in the bond rate appears as an explanatory variable in the equation determining the change in stock prices (with a negative sign). 
Consider now what happens when the bill rate increases. This increases the long term rates through the term structure equations. These interest rate increases have a direct negative effect on nondurable and durable consumption, housing investment, and imports. The fall in consumption and housing investment has a negative effect on GNP, but the fall in imports has a positive effect. The net effect could thus go either way, but it is in fact negative in the model.

The increase in the bond rate has a negative effect on stock prices, which lowers household wealth. Household wealth is an explanatory variable in the consumption and housing investment equations (with a positive sign), and so the decrease in wealth has a negative effect on consumption and housing investment. Household demand thus falls when interest rates rise for two main reasons. One is the direct negative effect of interest rates on demand, and the other is the indirect effect of interest rates affecting wealth and then wealth affecting demand.

offsetting these two negative effects in part (but only in part) is the fact that net interest payments to the household sector rise when interest rates rise. Interest payments to the household sector are part of nonlabor income, and nonlabor income is an explanatory variable in the consumption and housing investment equations (with a positive sign). Therefore, a rise in interest payments, other things being equal, leads to an increase in household demand.

So far no mention has been made of plant and equipment (P\&E) investment. The equation determining $P \& E$ investment is an accelerator-1ike equation, and the interest rate does not appear in this equation. I have been unable to find significant interest rate effects in this equation, 
although this is not from lack of trying. Interest rates do, however, have a negative effect on $P \& E$ investment in the model because they have a negative effect on output. In other words, interest rates affect $P \& E$ investment by first affecting household demand, which affects the level of sales, which affects production, which affects investment.

To summarize, interest rates do have important effects on the economy in the model. They directly and indirectly affect household demand (consumption and housing investment), which in turn affects sales, production, and P\&E investment.

As a final note about the model, in the stochastic simulation work account was taken of exogenous-variable uncertainty as well as uncertainty from the 29 stochastic structural equations. (There are 29 rather than 30 stochastic structural equations in the version of the model used in this paper because the interest rate reaction function is dropped.) Autoregressive equations were estimated for 23 exogenous variables in the model. These variables make up the main exogenous variables in the model. The autoregressive equations were eighth order and contained a constant and time trend. These 23 equations were then added to the model, resulting in a model with 52 stochastic equations. This is the version of the model that was stochastically simulated.

\section{Comparison of the Two Policy Instruments}

The Procedure

As noted in the Introduction, stochastic simulation can be used to estimate variances in econometric models. The Appendix describes the procedure that was used in this paper. The simulations were run over the 
eight-quarter period, 1981 III - 1983 II. A path of values of the interest rate (the bill rate) was chosen for this period, and this path was used for all the simulations in which the interest rate was the policy instrument. Similarly, a path of values of the money supply was chosen, and this path was used for all the simulations in which the money supply was the policy instrument. 3

There are two dimensions to the simulations. One is whether the interest rate or the money supply is the policy instrument. ${ }^{4}$ The other is how many of the 52 error terms are drawn for the stochastic simulation. For the complete simulation all 52 error terms are drawn. This is the simulation examined in this section. The notation $\tilde{\sigma}_{i t}^{2}(r, k)$ will refer to the stochastic simulation estimate of the variance of variable $i$ for period $t$ when the interest rate is the policy instrument and the simulation is based on draws of $k$ error terms. (As just noted, $k$ is 52 in this section.) The notation $\tilde{\sigma}_{i t}^{2}(M, k)$ will refer to the same thing when the money supply is the policy instrument. For many of the results in this paper, $i$ refers to real GNP.

The variance of real GNP for a given quarter corresponds to Poole's loss function if one takes the target value of GNP for that quarter to be

${ }^{3}$ It does not matter very much how these paths are chosen. In the present case they were chosen as follows. A dynamic simulation was first run over the eight-quarter period with the error terms set to zero. The predicted values of the bill rate from this simulation were then taken as the values for the interest rate path. Likewise, the predicted values of the money supply were taken as the values for the money supply path.

${ }^{4}$ When the money supply is the policy instrument, there is the further question of whether it is the nominal or real money supply that is the instrument. This question does not arise in Poole's analysis because the price level is exogenous. For purposes of this paper the nominal money supply is taken to be policy instrument. 
the mean value from the stochastic simulation. There is no harm in doing this, and so from now on Poole's loss function will be assumed to be the same as the variance of GNP. From the results one can compare the variances of GNP for the two policy instruments. If the variance is smaller when the interest rate is the policy instrument, this is evidence in favor of the interest rate, and vice versa if the variance is smaller when the money supply is the policy instrument.

It should be noted that variances are computed for each quarter of the eight-quarter simulation period. The simulations are dynamic, so that, for example, the computed variance for the fourth quarter is the variance of the four-quarter-ahead prediction error. Note also that when the interest rate is the policy instrument, the eight-quarter path for the interest rate is fixed across all simulation trials. The values in the path vary from one quarter to the next (they are the predicted values from the simulation with the error terms set to zero), but for a given quarter the value is the same across all trials. Similarly, when the money supply is the policy instrument, the eight-quarter path for the money supply is fixed across all simulation trials. This treatment means that monetary policy is assumed to be passive rather than active. The Fed is not assumed to change the interest rate or the money supply in response to past shocks to the economy (from the stochastic simulation). In practice the Fed is likely to respond, at least after a few quarters, and so the present experiment is not completely realistic. The experiment answers the question of what the optimal choice of the policy instrument is if the Fed behaves passively. Because of this, the results are likely to be more trustworthy for the first few quarters out than they are after that. 


\section{The Results}

The variances of real GNP for the two policy instruments are (the units of real GNP are billions of 1982 dollars):

Quarters Ahead

Real GNP:

$\begin{array}{lllllllll}1 & 2 & 3 & 4 & 5 & 6 & 7 & 8\end{array}$

$\begin{array}{lllllllll}\tilde{\sigma}_{i t}^{2}(r, 52): & 406.7 & 833.3 & 1310.7 & 1795.7 & 2379.0 & 2872.0 & 3573.7 & 3953.8\end{array}$

$\begin{array}{lllllllll}\tilde{\sigma}_{\text {it }}^{2}(M, 52): & 409.5 & 878.5 & 1380.0 & 1857.3 & 2430.5 & 2813.5 & 3388.4 & 3702.1\end{array}$

The subscript $i$ in this case refers to real GNP. $t$ always runs from 1981

III through 1983 II. Instead of discussing these results directly, it is easier to discuss them after they have been presented in terms of the percentage difference between the two variances:

$100 \cdot\left[\tilde{\sigma}_{i t}^{2}(M, 52)-\tilde{\sigma}_{i t}^{2}(r, 52)\right] / \tilde{\sigma}_{i t}^{2}(r, 52):$

Quarters Ahead

$\begin{array}{lllllllll}1 & 2 & 3 & 4 & 5 & 6 & 7 & 8\end{array}$

$\begin{array}{lcccccccc}\text { Real GNP } & .69 & 5.42 & 5.29 & 3.44 & 2.16 & -2.04 & -5.19 & -6.37 \\ & (.84) & (1.90) & (2.19) & (2.38) & (2.40) & (2.28) & (2.14) & (2.11)\end{array}$

The numbers in parentheses are standard errors of the percent differences. 5 They are a measure of the accuracy of the stochastic simulation estimates.

The results show that for the first five quarters the interest rate policy is better, and for the remaining three quarters the money supply policy is better. ${ }^{6}$ It is clear, however, that the differences are fairly

${ }^{5}$ The Appendix discusses the computation of the standard errors. The numbers in parentheses are actually the standard errors of the absolute differences (denoted $\operatorname{var}\left(\delta_{i t}\right)$ in the Appendix) divided by $\tilde{\sigma}_{i t}^{2}(r, 52)$.

6 By "interest rate policy" is meant the case in which the interest rate is the policy instrument, and by "money supply policy" is meant the case in which the money supply is the policy instrument. 
small. For the four-quarter-ahead prediction, for example, the variance of real GNP for the interest rate policy is only 3.44 percent greater than the variance for the money supply policy. As a practical matter these differences are close to being negligible.

As mentioned in the Introduction, the results for real GNP mask sone important differences for other variables. The following are percent differences for some of the other variables in the model: ${ }^{7}$

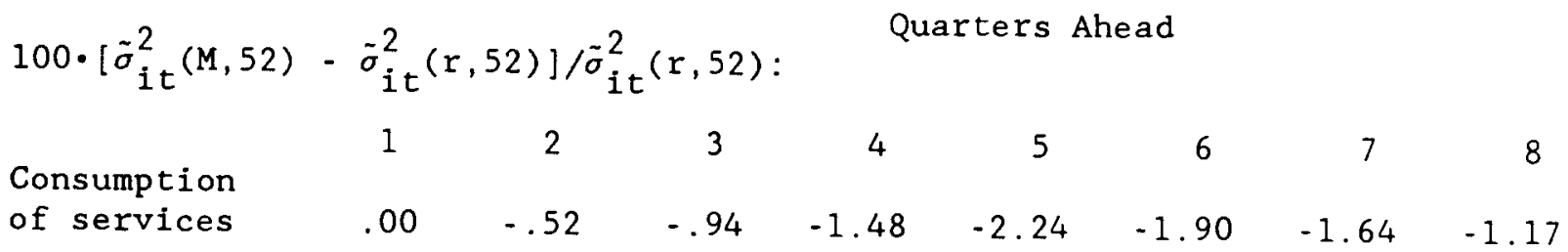

Consumption

$\begin{array}{lllllllll}\text { of nondurables } & .89 & 2.21 & 5.03 & 3.64 & 3.35 & 1.50 & .11 & 2.10\end{array}$

Consumption

$\begin{array}{lllllllll}\text { of durables } & 16.69 & 43.84 & 62.70 & 62.98 & 69.18 & 65.68 & 57.96 & 61.68\end{array}$

Housing

$\begin{array}{lllllllll}\text { Investment } & .00 & 12.27 & 28.89 & 33.68 & 39.68 & 39.51 & 38.52 & 41.43\end{array}$

Plant \& Equip.

$\begin{array}{llllllllll}\text { Investment } & -.55 & .10 & -.08 & -.76 & .11 & -2.45 & -3.94 & -5.27\end{array}$

$\begin{array}{lllllllll}\text { Investment } & -.46 & -.17 & .63 & .68 & .97 & .50 & -1.13 & -1.07\end{array}$

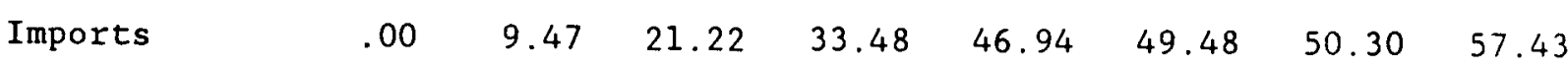

Change in

$\begin{array}{lllllllll}\text { Stock Prices } & 225.51 & 293.01 & 235.74 & 287.92 & 269.30 & 279.48 & 278.47 & 290.64\end{array}$ $\begin{array}{lllllllll}\text { Inflation } & & & & & & & & \\ \text { rate }^{\text {ation }} & .04 & .08 & .53 & .14 & -.91 & -.12 & -1.35 & -1.41\end{array}$

' 7 To conserve space, the standard errors of the differences are not presented. Enough trials were taken (1000) to make the standard errors small enough to allow meaningful comparisons to be made. See the discussion in the Appendix. points.

${ }^{8}$ Percentage change in the GNP deflator at an annual rate in percentage 
Unemployment

$\begin{array}{lrrrrrrrr}\text { rate } & 1.45 & 4.71 & 5.65 & 3.83 & 1.56 & -.24 & -3.61 & -5.64 \\ \text { Profits } & 24.05 & 13.69 & 10.99 & 7.47 & 6.86 & 3.41 & -1.12 & -.75\end{array}$

The three most interest sensitive components of GNP in the model are consumption of durables, housing investment, and imports, and it is clear for these three variables that the variances are much higher when the money supply is the policy instrument. For example, for the four-quarter-ahead prediction the variance of consumption of durables is 62.98 percent higher for the money supply policy. The variance of housing investment is 33.68 percent higher, and the variance of imports is 33.48 percent higher. The variances of the change in stock prices are considerably higher for the money supply policy, by a factor of around 2.5. The change in stock prices is also sensitive to the interest rate in the model.

The variance of the interest rate for a given quarter is obviously larger for the money supply policy than it is for the interest rate policy. It is zero for the interest rate policy. For the money supply policy the standard deviations of the bill rate for the eight quarters (in percentage points) are respectively: $3.31,3.29,3.25,3.43,3.38,3.49,3.44$, and 3.52. These are large deviations. ${ }^{9}$ It should be noted, however, that a larger variance of the interest rate does not imply that the variances of even the interest sensitive variables in the model are larger. It may be that the parameters, variances of the error terms, and covariances of the

${ }^{9}$ For sake of completeness, the standard deviations of the money supply for the interest rate policy should be noted. The standard deviations of the money supply as a percent of the mean values of the money supply in the eight quarters in percentage points are respectively: .90, $1.26,1.51,1.71$, $1.87,2.02,2.16$, and 2.32 . 
error terms in the model are such as to lead the interest sensitive variables to have smaller variances even though the interest rate has a larger variance. This is not the case in my model, however, since it is clear that the interest sensitive variables have larger variances for the money supply policy.

Given that the interest sensitive components of real GNP have considerably larger variances for the money supply policy, it is interesting and perhaps somewhat surprising that the variances of real GNP are so close for the two policies. One of the reasons for this is the following. Consider for the money supply policy a shock to one of the demand for money equations that leads to an increase in the interest rate. This has a direct negative effect on consumption, housing investment, and the demand for imports. The fall in consumption and housing investment has a negative effect on GNP, but the fall in imports has a positive effect. The net effect on GNP is thus smaller than would be the case if all the components affected GNP in the same direction. In other words, negative interest rate effects on consumption and housing investment are in part offset by negative effects on imports.

In order to get an idea of the size of the offsetting import effect, the two stochastic simulations were run with the import equation dropped. In other words, the level of imports was taken to be exogenous. The percentage differences between the two variances for real GNP for the eight quarters in this case were respectively: $.92,10.08,14.05,15.23,16.22$, $11.73,5.87$, and 4.33 . In this case the interest rate policy does noticeably better. For the four-quarter-ahead prediction, for example, when the import equation is dropped, the variance of real GNP for the money 
supply policy is 15.23 percent higher than it is for the interest rate policy. This compares to only 3.44 percent when the import equation is included in the model. Dropping the import equation is, of course, not a realistic thing to do. This experiment is only meant to get an idea of the size of the offsetting import effect.

Another way of looking at this import experiment is the following. Dropping the import equation has the effect of making real GNP more sensitive to the interest rate. This is similar in Poole's analysis to making the coefficient of the interest rate variable in the Is function larger in absolute value. Does this help or hurt the interest rate policy relative to the money supply policy? This depends on the sizes of the parameters and of the variances and covariances of the error terms. The effect could go either way. The results of the import experiment suggest that in my model the interest rate policy is helped relative to the money supply policy when the sensitivity of GNP to the interest rate is increased. This means, for example, that if the equation explaining P\&E investment in the model were replaced with one in which the interest rate played an important role, the interest rate policy would probably improve relative to the money supply policy. This is, of course, not certain, since the answer depends on all the parameters, variances, and covariances in the model.

To conclude, the results favor the interest rate policy if one considers variances of variables other than real GNP. For real GNP alone, the two policies give similar results. 
IV. Contribution of the Error Terms in the Demand for Money Equations to the Variance of Real GNP

It is interesting to consider the case in which the error terms in the four money equations are zero across all trials. This is meant to correspond as close as possible to Poole's case of no error term in the LM function. One can compare the variance of real GNP from the simulation in which the error terms from all 52 equations are drawn with the simulation in which the error terms from the 48 non-money equations are drawn. The percentage difference between these two variances is an estimate of how much the error terms in the money equations contribute to the variance of GNP. For the money supply policy the percentage differences are: ${ }^{10}$

$100 \cdot\left[\tilde{\sigma}_{i t}^{2}(M, 52)-\tilde{\sigma}_{i t}^{2}(M, 48)\right] / \tilde{\sigma}_{i t}^{2}(M, 52): \quad$ Quarters Ahead

$\begin{array}{llllllll}1 & 2 & 3 & 4 & 5 & 6 & 7 & 8\end{array}$

$\begin{array}{llllllllll}\text { Real GNP } & .78 & 5.74 & 6.77 & 6.13 & 6.00 & 2.77 & 0.00 & -.31\end{array}$

These differences are small. The largest difference is only 6.77 percent, which says that only 6.77 percent of the variance of GNP is due to the error terms in the money equations.

Because of the correlation of the error terms across equations, dropping the error terms in, say, four equations and seeing how much the variance of GNP changes is not the same as computing the variance of GNP by drawing only the error terms from the four equations. To see how much difference this makes, a stochastic simulation was performed in which only the error terms in the four money equations were drawn. All the other error terms were fixed at zero. The variances of GNP in this case as a

${ }^{10}$ For the interest rate policy the differences are negligible, as expected from Poole's analysis. 
percent of the variances of GNP when all the error terms are drawn are:

$100 \cdot\left[\tilde{\sigma}_{i t}^{2}(M, 4) / \tilde{\sigma}_{i t}^{2}(M, 52)\right]:$

Quarters Ahead

$\begin{array}{llllllll}1 & 2 & 3 & 4 & 5 & 6 & 7 & 8\end{array}$

$\begin{array}{lllllllll}\text { Real GNP } & 1.73 & 8.62 & 12.16 & 13.66 & 13.35 & 13.36 & 12.14 & 11.79\end{array}$

The estimated contribution is greater when computed this way, al though the estimates are still fairly small. For the four-quarter-ahead prediction, for example, the contribution is 13.66 percent rather than 6.13 percent. One final experiment is of interest here. In Poole's analysis if the variance of the error term in the LM function is zero and the coefficients are of the expected sign, then the loss from using the money supply as the policy instrument is less than the loss from using the interest rate. It is interesting to see if something like this holds in the present model. This experiment can be performed by comparing the variance of real GNP for the money supply policy when the error terms in the money equations are fixed at zero to the variance of real GNP for the interest rate policy when the error terms in the money equations are fixed at zero. ${ }^{11}$ The percentage differences between the two variances are:

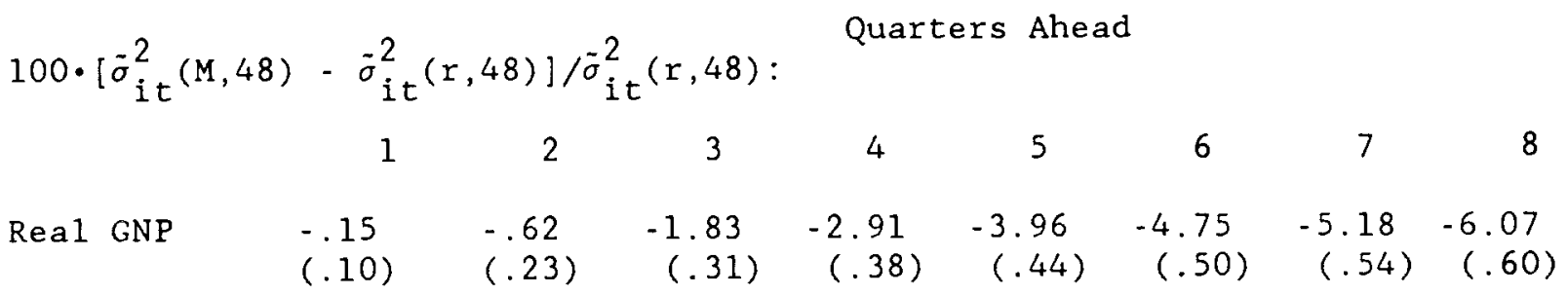

The numbers in parentheses are again standard errors of the differences.

The differences are all negative, as expected from the Poole analysis,

${ }^{11}$ As noted in the previous footnote, the variance of real GNP for the interest rate policy is negligibly affected by fixing the error terms in the mgney equations at zero. In other words, $\tilde{\sigma}_{i t}^{2}(r, 52)$ is nearly identical to $\tilde{\sigma}_{i t}^{2}(r, 48)$ for $i$ equal to real GNP. 
although again they are fairly small. One way of putting this is that the gain for the money supply policy of there being no errors in the money equations is fairly small.

\section{Conclusion}

This study has shown that stochastic simulation can be used to consider the optimal choice of monetary policy instruments in econometric models. The results for my model provide some support for what seems to be the Fed's current choice of using the interest rate as its primary instrument. The results also show that the contribution of the error terms in the demand for money equations to the variance of real GNP is not very great even when the money supply is the policy instrument.

The present results obviously depend on the properties of my model, and it would be of interest to see if similar results hold for other models. If the present results are biased, there are at least two reasons for thinking that they may be biased against the interest rate policy. First, as noted in Section III, if the interest rate directly affected plant and equipment investment in the model, thus increasing the sensitivity of real GNP to the interest rate, this would probably favor the interest rate policy over the money supply policy. Second, the exchange rate is exogenous in the model used in this paper. If it were endogenous and were influenced by the interest rate, then its variance is likely to be greater for the money supply policy. This larger variance may then lead to a larger variance of real GNP. This, of course, does not necessarily follow, since the net effect depends on all the parameters, variances, and covariances in the model. At any rate, the robustness of the results to the use of alternative models and specifications needs to be examined in future work. 


\section{APPENDIX}

The use of stochastic simulation to estimate variances in nonlinear econometric models is discussed in this Appendix. Write the model as

$$
f_{i}\left(y_{t}, x_{t}, \alpha_{i}\right)=u_{i t}, i=1, \ldots, n, t=1, \ldots, T
$$

where $y_{t}$ is an $n$-dimensional vector of endogenous variables, $x_{t}$ is a vector of predetermined variables, $\alpha_{i}$ is a vector of unknown coefficients, and $u_{i t}$ is an error term. The first m equations are assumed to be stochastic, with the remaining $u_{i t}(i=m+1, \ldots, n)$ identically zero for all $t$. It is assumed that $u_{t}=\left(u_{1 t}, \ldots, u_{m t}\right)$ is independently and identically distributed as multivariate normal $\mathrm{N}(0, \Sigma) .^{12}$ It is also assumed that consistent estimates of $\alpha_{i}$, denoted $\hat{\alpha}_{i}$, are available for all $i$. Given these estimates, consistent estimates of $u_{i t}$, denoted $\hat{u}_{i t}$, can be computed as $f_{i}\left(y_{t}, x_{t}, \hat{\alpha}_{i}\right)$. The covariance matrix $\Sigma$ can then be estimated as $(1 / T) U U^{\prime}$, where $U$ is the $m$ $x$ T matrix of the values of $\hat{\mathrm{u}}_{i t}$.

Let $u_{t}^{*}$ denote a particular draw of the m error terms for period $t$ from the $N(0, \hat{\Sigma})$ distribution. Given $u_{t}^{*}$ and given $\hat{\alpha}_{i}$ for all $i$, one can solve the model for period $t$. This is merely a deterministic simulation for the given values of the error terms and coefficients. Call this simulation a "trial." Another trial can be made by drawing a new set of values of $u_{t}^{*}$ and solving again. This can be done as many times as desired. From each trial one obtains a prediction of each endogenous variable. Let $y_{i t}^{j}$ denote the value on the $j$ th trial of variable $i$ for period $t$. For $J$ trials, the stochastic

${ }^{12}$ Although the normality assumption is used in this paper, other assumptions could be used. This would simply change the way the error terms are drawn. 
simulation estimate of the expected value of variable $i$ for period $t$, denoted $\tilde{\mu}_{i t}$, is

(A2) $\tilde{\mu}_{i t}=(1 / J) \sum_{j=1}^{J} y_{i t}^{j}$.

Let

(A3) $\sigma_{i t}^{2 j}=\left(y_{i t}^{j}-\tilde{\mu}_{i t}\right)^{2}$.

The stochastic simulation estimate of the variance of variable $i$ for period $t$, denoted $\tilde{\sigma}_{i t}^{2}$, is then

(A4) $\tilde{\sigma}_{i t}^{2}=(1 / \mathrm{J}) \underset{\mathrm{j}=1}{\mathrm{~J}} \sigma_{i \mathrm{t}}^{2 \mathrm{j}}$.

Given the data from the trials, it is also possible to compute the variances of the stochastic simulation estimates. The variance of $\tilde{\mu}_{i t}$, for example, is $\tilde{\sigma}_{i t}^{2} / J$. The variance of $\tilde{\sigma}_{i t}^{2}$, denoted $\operatorname{var}\left(\tilde{\sigma}_{i t}^{2}\right)$, is

(A5) $\operatorname{var}\left(\tilde{\sigma}_{i t}^{2}\right)-(1 / \mathrm{J})^{2} \sum_{j=1}^{\mathrm{J}}\left(\sigma_{i t}^{2 j}-\tilde{\sigma}_{i t}^{2}\right)^{2}$.

For some work, as in this paper, one is interested in the difference between two estimated variances. Let $\tilde{\sigma}_{i t}^{2}$ (a) be one estimated variance, let $\tilde{\sigma}_{i t}^{2}$ (b) be another, and let $\delta_{i t}$ be the difference between the two:

(A6) $\delta_{i t}=\tilde{\sigma}_{i t}^{2}(a)-\tilde{\sigma}_{i t}^{2}(b)$.

$a$ and $b$ correspond to two different experiments -. for example, one in which the interest rate is the policy instrument and one in which the money supply is the policy instrument or one in which all the error terms are drawn and one in which only some of the error terms are drawn.

It is also possible to compute the variance of the difference, denoted 
$\operatorname{var}\left(\delta_{i t}\right) \cdot$ First, let

(A7) $\mathrm{d}_{\mathrm{it}}^{\mathrm{j}}=\sigma_{\mathrm{it}}^{2 \mathrm{j}(a)}-\sigma_{\mathrm{it}}^{2 \mathrm{j}}(\mathrm{b})$.

From $(A 4),(A 6)$, and $(A 7), \delta_{i t}$ can be written

(A8) $\delta_{i t}=(1 / J) \sum_{j=1}^{J} d_{i t}^{j}$.

The variance of $\delta_{i t}$ is then

(A9) $\operatorname{var}\left(\delta_{i t}\right)=(1 / J)^{2} \sum_{j=1}^{J}\left(d_{i t}^{j}-\delta_{i t}\right)^{2}$.

Given $y_{i t}^{j}(a)$ and $y_{i t}^{j}(b), j=1, \ldots, J$, all the above values can be computed.

In many applications, as in the present study, one is interested in predicted values more than one period ahead, i.e. in predicted values from dynamic simulations. The above discussion can be easily modified to incorporate this case. One simply draws values for $u_{t}$ for each period of the simulation. Each trial is one dynamic simulation over the period of interest. For, say, an eight-quarter period, each trial yields eight predicted values, one per quarter, for each endogenous variable.

Although not done in this paper, it is also possible to draw coefficients for the trials. Given an estimate of the distribution of the coefficient estimates, which one has from the estimation of the model, coefficient values can be drawn. In this case each trial consists of draws of error terms and coefficients.

Regarding exogenous variables, if the exogenous-variable values are the same from trial to trial, then the estimated variances are conditional on fixed values of the exogenous variables. It is also possible, however, to take into account exogenous-variable uncertainty. There are a number of 
ways to do this. For purposes of this paper, equations explaining the main exogenous variables in model were added to the model. An eighth order autoregressive equation (with a constant term and time trend included) was estimated for each exogenous variable of interest and these equations were added to the model. Stochastic simulation can then be done for this expanded version of the model. By drawing error terms from the equations explaining the exogenous variables, exogenous-variable uncertainty is taken into account.

Assume that there are $q$ exogenous-variable equations added to the mode1. This means that the covariance matrix $\Sigma$ is now $(m+q) x(m+q)$. In estimating this matrix one may want to take $\Sigma$ to be block diagonal, where the first block is the original $\mathrm{m} \times \mathrm{m}$ matrix and the second block is the $q \times q$ estimated covariance matrix of the error terms in the exogenous. variable equations. This procedure is consistent with the assumption upon which the estimation of the model is based. This procedure was used for the results in this paper.

Stochastic-simulation error can be large when comparing differences of variances. In the present case 1000 trials was enough to make $\operatorname{var}\left(\tilde{\sigma}_{i t}^{2}\right)$ acceptably small, but without any tricks, it was not enough to make $\operatorname{var}\left(\delta_{i t}\right)$ anywhere close to being acceptably small. Fortunately, there is an easy trick available. The variance of $\delta_{i t}$ is equal to the variance of $\sigma_{i t}^{2}$ (a) plus the variance of $\tilde{\sigma}_{i t}^{2}(b)$ minus twice the covariance. The trick is to make the covariance high, which can be done by using the same draws of the error terms for the computation of both $\tilde{\sigma}_{i t}^{2}(a)$ and $\tilde{\sigma}_{i t}^{2}(b)$. Any one equation of the model, for example, requires 8000 draws of its error term for 1000 trials for a forecast horizon of 8 quarters. If these same 8000 numbers are 
used to compute both $\tilde{\sigma}_{i t}^{2}(a)$ and $\tilde{\sigma}_{i t}^{2}(b)$, the covariance between them will be increased. When this trick is used, 1000 trials leads to values of $\operatorname{var}\left(\delta_{i t}\right)$ that are acceptably small. Each eight-quarter simulation of 1000 trials takes about 5 hours of CPU time on a VAX 730 for my model. 
REFERENCES

Fair, Ray C., Specification, Estimation, and Analysis of Macroeconometric Models, Cambridge: Harvard University Press, 1984.

Poole, William, "Optimal Choice of Monetary Policy Instruments in a Simple Stochastic Macro Model," Quarterly Journal of Economics, 84 (1970), $197-216$.

Tinsley, P. A., and P. von zur Muehlen, "Conditional Intermediate Targeting," mimeo, 1983.

Turnovsky, S., "Optimal Choice of Monetary Instrument in a Linear Economic Model with Stochastic Coefficients," Journal of Money. Credit, and Banking, 7 (1975), 51-80.

Yoshikawa, H., "Alternative Monetary Policies and Stability in a Stochastic Keynesian Model," International Economic Review, 22 (1981), 541-565. 